\title{
Simultaneous improvement in production of microalgal biodiesel and high-value alpha-linolenic acid by a single regulator acetylcholine
}

\author{
Ali Parsaeimehr ${ }^{1}$, Zhilan Sun ${ }^{1}$, Xiao Dou ${ }^{2}$ and Yi-Feng Chen ${ }^{{ }^{*}}$
}

\begin{abstract}
Background: Photoautotrophic microalgae are a promising avenue for sustained biodiesel production, but are compromised by low yields of biomass and lipids at present. We are developing a chemical approach to improve microalgal accumulation of feedstock lipids as well as high-value alpha-linolenic acid which in turn might provide a driving force for biodiesel production.

Results: We demonstrate the effectiveness of the small bioactive molecule "acetylcholine" on accumulation of biomass, total lipids, and alpha-linolenic acid in Chlorella sorokiniana. The effectiveness exists in different species of Chlorella. Moreover, the precursor and analogs of acetylcholine display increased effectiveness at higher applied doses, with maximal increases by 126,80 , and $60 \%$ over controls for biomass, total lipids, and alpha-linolenic acid, respectively. Production of calculated biodiesel was also improved by the precursor and analogs of acetylcholine. The biodiesel quality affected by changes in microalgal fatty acid composition was addressed.

Conclusion: The chemical approach described here could improve the lipid yield and biodiesel production of photoautotrophic microalgae if combined with current genetic approaches.
\end{abstract}

Keywords: Acetylcholine, Chlorella sorokiniana U2-9, Lipids, Alpha-linolenic acid, Biodiesel

\section{Background}

Energy consumption is dramatically increasing, and the global energy demand is estimated to grow by more than $85 \%$ by 2040 . Fossil fuel resources provide most of the world's energy demands but are limited, and thus additional sources of energy must be considered. Biofuels have the potential to supply a portion of our society's energy demands. Biodiesel is a diesel fuel derived from animal or plant oils and is composed of methyl esters of long-chain fatty acids produced by transesterification of lipids [1].

Microalgae have the capacity to generate considerable amounts of biomass and lipids, which can be used for biodiesel production and are also of potential use for human health [2,3]. Microalgae offer excellent sources of polyunsaturated fatty acids (PUFAs), including docosahexaenoic acid (DHA, C22:6), eicosapentaenoic acid (EPA, C20:5), arachidonic acid (ARA, C20:4) and alpha-linolenic

\footnotetext{
* Correspondence: yifchen@hotmail.com

'Laboratory of Biosystems Engineering, Institute of Biotechnology, Jiangsu

Academy of Agricultural Sciences, Nanjing 210014, Jiangsu, China

Full list of author information is available at the end of the article
}

acid (ALA, C18:3) [4,5]. These essential fatty acids are important to human health and must be consumed regularly, since they cannot be synthesized by humans [6-8].

A recent pharmacological survey suggested that small bioactive molecules might be effective in microalgal lipid accumulation [9]. We examined the feasibility of this approach using the small bioactive molecule acetylcholine (ACh). ACh is an organic compound and is probably one of the most evolutionarily ancient signaling molecules. $\mathrm{ACh}$ is best known as a canonical neurotransmitter and plays a fundamental function in the neurotransmission process in animals and insects $[10,11]$. However, ACh is also likely to play a role in non-neuronal signaling, as it is found in a range of organisms including plants, algae, fungi, protozoa, and bacteria. In plants, ACh exhibits stimulatory roles in flowering, stomatal movements, and phytochrome action, as well as inhibitory roles in ethylene production and leaf rolling [12-15]. ACh is also reported to stimulate growth in Vigna sesquipedalis, Raphanus sativus, Phyllostachys bambusoides, Triticum aestivum, and Lycopersicon esculentum [16-19]. Light has a regulatory role in 
ACh production, and ACh plays the roles of cholinergic agonist and antagonist in the growth and differentiation in the green alga Micrasterias denticulata [20]. Choline and acetyl coenzyme-A are responsible for ACh synthesis mediated by the enzyme choline acetyltransferase (ChAT) $($ Choline + Acetyl coenzyme $\mathrm{A} \rightleftharpoons$ Acetylcoline + Coenzyme A). Since the rate of ACh biosynthesis is correlated to the presence of $\mathrm{ACh}$ precursor and associated enzymes, ACh can influence the biosynthesis process by regulating enzymes such as ChAT, acetyl-CoA carboxylase, choline kinase, cholinesterase, and pseudocholinesterase $[21,22]$. Reports have pointed to the existence of ACh in $0.2 \mu \mathrm{g} \mathrm{g}^{-1}$ of dry weight in microalgae species such as Micrasterias denticulata and Laurencia obtusa, even though ACh was only detectable when extracts were pre-treated by ACh-esterase inhibitor [20,23]. ACh and its chemical analog taurine had significant stimulations on some metabolites of Chlorella vulgaris, although ACh had a superior activity on production of monosaccharides and soluble proteins [24]. In this study, we report that $\mathrm{ACh}$ improves the efficiency for accumulation of microalgal lipids and ALA, a valuable compound in Chlorella sorokiniana U2-9. The effectiveness of ACh significantly improved lipid production in a variety of microalgal species.

\section{Results and discussion}

\section{Chlorella sorokiniana U2-9 dominantly performs}

\section{photoautotrophic growth under light in TAP medium}

In this study, Tris-Acetate-Phosphate (TAP) medium was used to culture C. sorokiniana U2-9. The inclusion of acetate in the medium might potentially support several metabolic pathways, including heterotrophy, photoautotrophy, or photomixotrophy. Therefore, two sets of experiments were performed to clarify that photoautotrophic growth is dominant in TAP medium. In the first set of experiments, biomass was much higher $(2.5 \pm$ $\left.0.4 \mathrm{~g} \mathrm{~L}^{-1}\right)$ in the light than in the dark $\left(0.9 \pm 0.3 \mathrm{~g} \mathrm{~L}^{-1}\right)$, indicating that light is an undeniable factor for growth of Chlorella. In the second experiment, an obvious stimulation of biomass was observed by a higher dose of $\mathrm{CO}_{2}$ (for example, $3.8 \pm 0.5 \mathrm{~g} \mathrm{~L}^{-1}$ at $5 \% \mathrm{CO}_{2}$ ) compared to the culture with air aeration $\left(2.5 \pm 0.4 \mathrm{~g} \mathrm{~L}^{-1}\right)$, indicative of $\mathrm{CO}_{2}$ dependence of Chlorella growth. Taken together, this means that TAP medium mostly supports the growth of Chlorella by photosynthesis, and covers a relatively simple mode of metabolism which could be suitable for the evaluation of ACh effects.

\section{Multiple effects of acetylcholine on Chlorella sorokiniana U2-9 and derived biodiesel}

The comprehensive positive effects of ACh on growth, lipid content, and lipid profiling of the Chlorella species were examined and revealed. An increase in dry weight was observed with 5 and $10 \mu \mathrm{g} \mathrm{L}^{-1}$ doses of ACh at the initial growth phase of C. sorokiniana U2-9, and the dry weight was increased by $26.38 \pm 2 \%$ in comparison to the control. Nevertheless, the usage of ACh at the exponential phase (day $\left.4, \mathrm{OD}_{680}=1.62 \pm 0.15\right)$ of algal growth was more effective, and higher dry weight $\left(3.2 \pm 0.15 \mathrm{~g} \mathrm{~L}^{-1}\right)$ was obtained with a $10 \mu \mathrm{g} \mathrm{L}^{-1}$ dosage of ACh. Using different doses of $\mathrm{ACh}$ at the stationary phase of $C$. sorokiniana growth (day $9, \mathrm{OD}_{680}=2.82 \pm 0.1$ ) had no effect on algal growth; however, higher applied doses of ACh $\left(100 \mu \mathrm{g} \mathrm{L}^{-1}\right)$ showed a rapid and negative effect, similar to an algicide.

The lipid content improved from $214.3 \pm 14 \mathrm{mg} \mathrm{g}^{-1}$ of dry weight to $303.3 \pm 27 \mathrm{mg} \mathrm{g}^{-1}$ of dry weight (lipid productivity of $80 \pm 6 \mathrm{mg} \mathrm{L}^{-1}$ day $^{-1}$ ) using a $5 \mu \mathrm{g} \mathrm{L} \mathrm{g}^{-1}$ dose of $\mathrm{ACh}$ at the initial phase of $C$. sorokiniana growth, but was decreased to $190 \pm 10 \mathrm{mg} \mathrm{g}^{-1}$ of dry weight with a $10 \mu \mathrm{g} \mathrm{L}{ }^{-1}$ dosage of ACh. ACh supplied at the exponential growth phase of C. sorokiniana demonstrated a greater influence on lipid production, and the total lipid content was increased up to $312 \pm 54 \mathrm{mg} \mathrm{g}^{-1}$ of dry weight with a $5 \mu \mathrm{g} \mathrm{L}^{-1}$ dosage of ACh (lipid productivity of $92 \pm 10 \mathrm{mg} \mathrm{L}^{-1}$ day $^{-1}$, and an increase by $45.8 \%)$. Nevertheless, with a $10 \mu \mathrm{g} \mathrm{L} \mathrm{L}^{-1}$ dosage of ACh the total lipid content and lipid productivity were reduced by 23.9 and $59.6 \%$ (total lipid content: $163.3 \pm 20.8 \mathrm{mg} \mathrm{g}^{-1}$ of dry weight, lipid productivity: $52 \pm 8 \mathrm{mg} \mathrm{L}^{-1}$ day $^{-1}$ ). These results revealed that the ACh stimulation on the microalgal growth and lipid accumulation is growth phase- and dose-dependent.

(See Table 1 and Additional file 1: Table S-1).

The GC analysis showed that the major components of fatty acids in C. sorokiniana U2-9 were palmitic acid (C16:0), stearic acid (C18:0), oleic acid (C18:1), linoleic acid (C18:2), and ALA (C18:3). During the growth of microalgae these components were altered slightly; for example, ALA (C18:3) was increased from 14.7 to 18.7\%. However, the treatment of microalgae with ACh

Table 1 Effectiveness of acetylcholine on Chlorella sorokiniana U2-9

\begin{tabular}{|c|c|c|c|c|c|c|c|}
\hline & \multicolumn{7}{|c|}{$A C h\left(\mu \mathrm{g} \mathrm{L}^{-1}\right)$} \\
\hline & 0 & 0.125 & 0.25 & 0.5 & 1 & 5 & 10 \\
\hline Dry weight $\left(\mathrm{gL}^{-1}\right)$ & $2.16 \pm 0.2$ & $2.2 \pm 2$ & $2.2 \pm 0.2$ & $2.4 \pm 0.17$ & $2.43 \pm 0.2$ & $2.73 \pm 0.1$ & $2.66 \pm 0.15$ \\
\hline Total lipid content ( $\mathrm{mg} \mathrm{g}^{-1}$ of dry weight) & $214.3 \pm 14$ & $223.3 \pm 16$ & $231.6 \pm 12$ & $252 \pm 10$ & $296 \pm 26$ & $303 \pm 24$ & $190 \pm 12$ \\
\hline Lipid productivity $\left(\mathrm{mgL}^{-1}\right.$ day $\left.^{-1}\right)$ & $46.4 \pm 6$ & $49.3 \pm 7$ & $50.8 \pm 4$ & $60.5 \pm 4$ & $72.4 \pm 8$ & $82.8 \pm 6$ & $50.7 \pm 5$ \\
\hline
\end{tabular}

Note: Acetylcholine was more efficient at doses of 0.5 to $5 \mu \mathrm{g} \mathrm{L}^{-1}$, but it exposed negative effects on lipid content and lipid productivity at $10 \mu \mathrm{L} \mathrm{L}^{-1}$. ACh was added at the initial phase of algal growth. All data were given as mean \pm standard error $(n=3)$ of three separated tests. 
significantly improved the relative content of ALA. ACh supplied in the initial phase of C. sorokiniana growth enhanced the relative content of ALA by $61.2 \%$, resulting in an increase of the PUFAs up to $50 \%$ of the fatty acids profile, and also in an increase of the biodiesel yield from $17.7 \pm 6 \%$ to $30.9 \pm 7 \%$ over the controls. Similar effects of ACh were also generated when ACh was supplied in the stationary phase of microalgal growth (Additional file 1: Table S-2).

Since the ratio of saturated to unsaturated fatty acids of the lipid profiling determines the quality of microalgal biodiesel, and since the relative contents of the microalgal fatty acid profile were altered by $\mathrm{ACh}$, we calculated the biodiesel properties and estimated $\mathrm{ACh}$ influences on the iodine value (IV), the cold filter plugging point (CFPP), and the cetane number $(\mathrm{CN})$; these parameters are closely associated with the biodiesel quality. The $\mathrm{CN}$ of biodiesel is linked to the ignition quality; a shorter ignition time is associated with an increase of the $\mathrm{CN}$. The IV shows the biodiesel vulnerability to oxidative attacks and is connected to numbers and positions of double bonds in the carbon chains of alkyl esters. The CFPP indicates the flow performance of biodiesel at low temperatures and is linked to the amounts of unsaturated fatty acids in biodiesel [25]. In general, we observed that the IV was enhanced and the CFPP was reduced in biodiesels from the ACh-treated samples, implying an improvement in the stability of biodiesel (Additional file 1: Table S-2). In contrast, the $\mathrm{CN}$ was almost not affected by the ACh treatments. If the ALA was removed from the fatty acid profile, the $\mathrm{CN}$ of the derived biodiesel could be greatly increased (Figure 1e, Figure 2e, Table 2).

\section{Effectiveness of acetylcholine was confirmed stable at different levels of Tris acetate and phosphate buffer}

We further examined the stability of the ACh effects under varied culture conditions. For this purpose, different levels of Tris acetate and phosphate buffer were used to investigate whether the influence of $\mathrm{ACh}$ is stable on C. sorokiniana U2-9 through culture. Increases in concentrations of the Tris acetate and phosphate buffer improved the biomass yields, although the total lipid content, the lipid productivity, and the ALA yield were reduced or not changed at the fourfold dose of Tris acetate or the threefold dose of phosphate buffer. Under the complex situation, ACh could still further enhance the dry weight, the lipid content, the lipid productivity, the ALA level, and the biodiesel yield (Figures 3 and 4), supporting a consistent role of ACh. Interestingly, the biodiesel properties were similar to previous results (Additional file 1: Table S-2); that is, the IV was increased and the CFPP was decreased in the ACh-treated samples with increased levels of Tris acetate and phosphate buffer (Additional file 1: Tables S-3 and S-4).

\section{Pharmacological examination implied a role of an endogenous $\mathrm{ACh}$}

The amount of $8.6 \pm 0.24 \mu \mathrm{g} \mathrm{g}^{-1}$ of dry weight of ACh was identified in C. sorokiniana U2-9 by using a quantitative

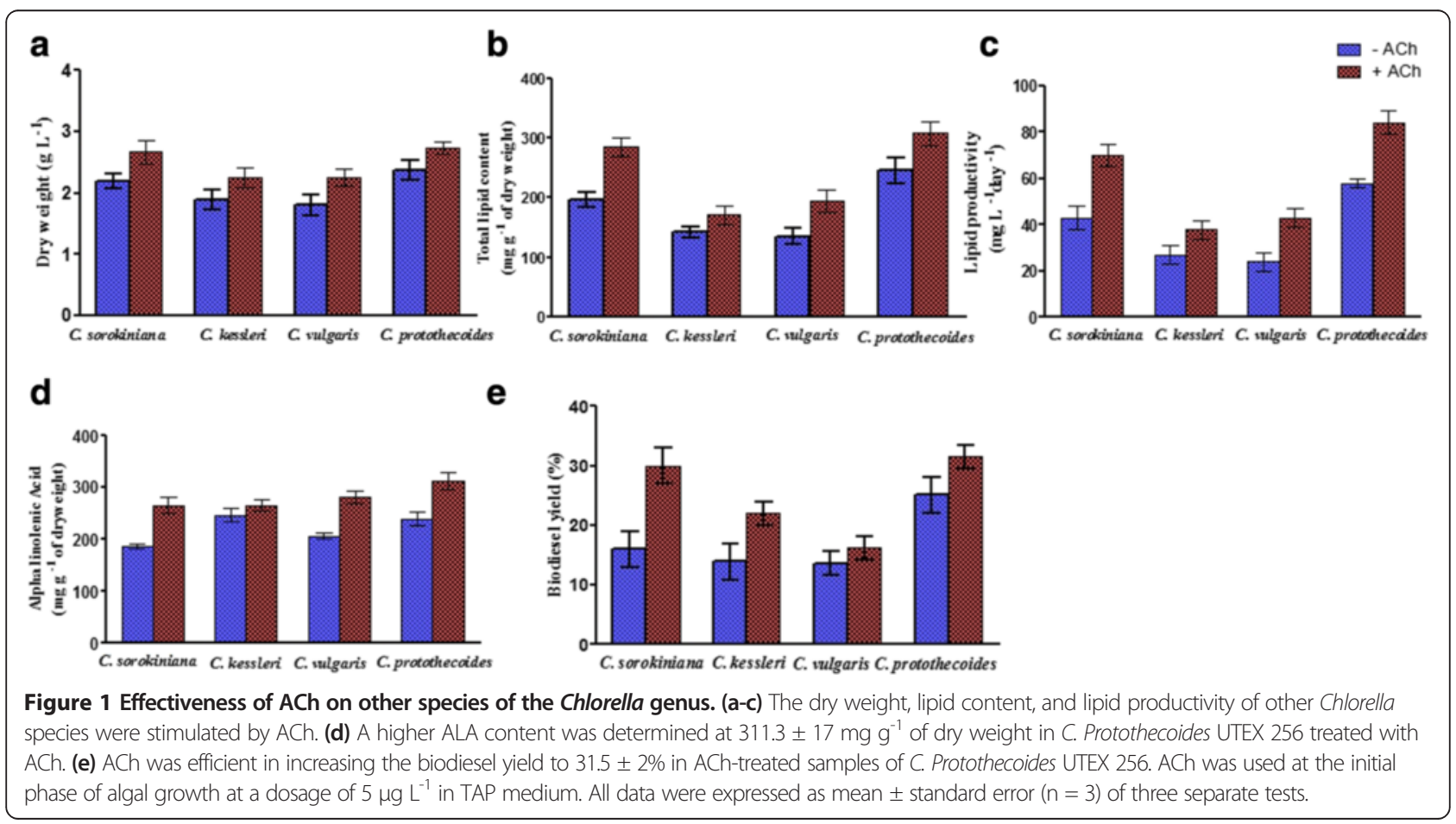




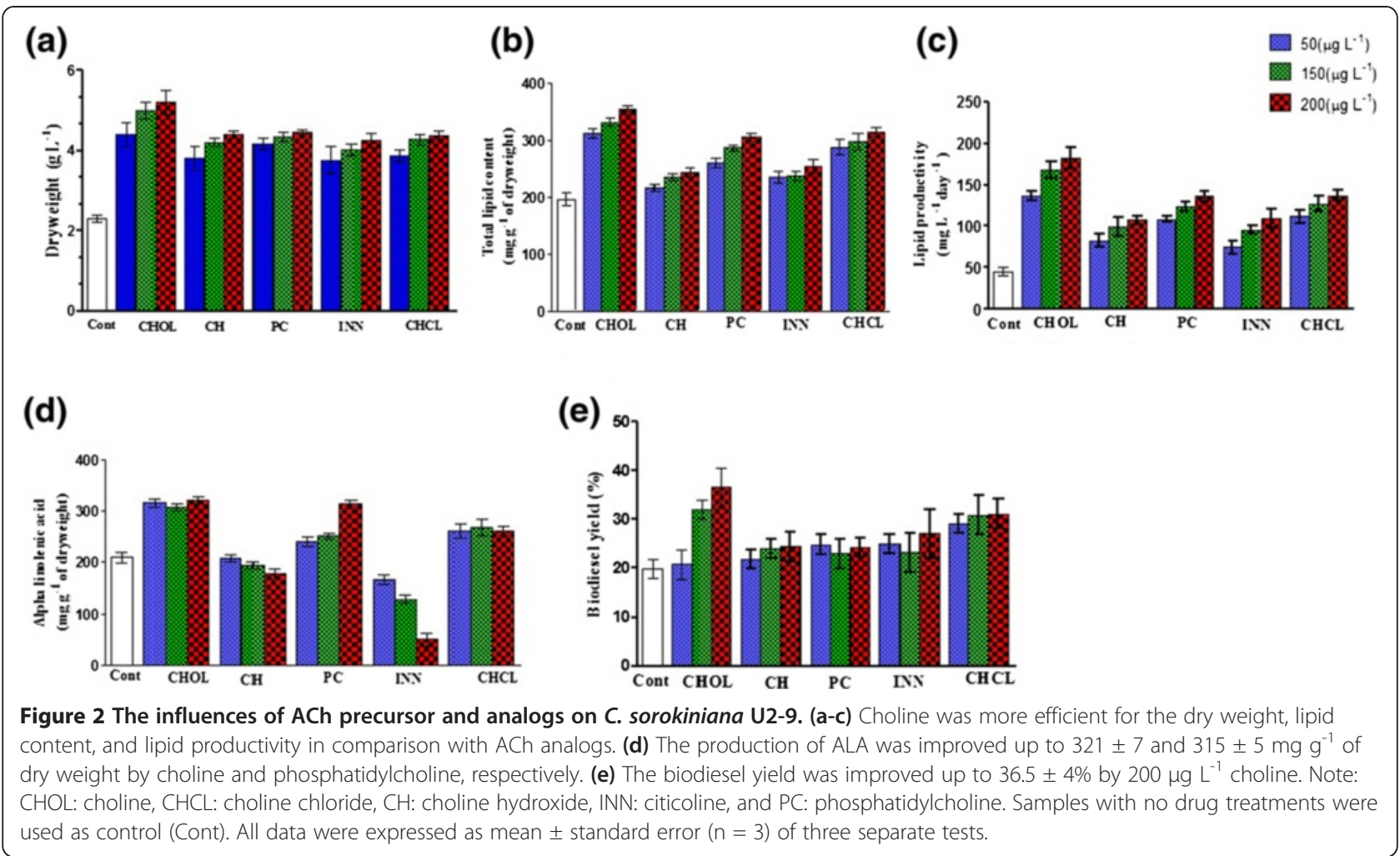

colorimetric/fluorometric test. As shown in Figure 5, with the addition of 0.025 to $0.5 \mu \mathrm{g} \mathrm{L}^{-1}$ doses of $\mathrm{AChE}$ (acetylcholine inhibitor) to the ACh-pretreated samples, the dry weight and the lipid content were decreased by 12 to $50 \%$ and 15 to $45 \%$, respectively. The effectiveness of ACh on ALA production was also neutralized by a $0.5 \mu \mathrm{g} \mathrm{L}^{-1}$ dosage of AChE (Table 3). The obtained results probably support the idea that endogenous $\mathrm{ACh}$ could have functions to improve biomass, lipids, and ALA contents of microalgae.

Table 2 Estimation of biodiesel properties based on fatty acid profiles in included and excluded ALA treatments

\begin{tabular}{|c|c|c|c|c|c|c|c|}
\hline & & SV & IV & DU & LCSF & CFPP $\left({ }^{\circ} \mathrm{C}\right)$ & $\mathrm{CN}$ \\
\hline \multirow[t]{7}{*}{ Included ALA } & Control & 210.9 & 133.8 & 122.9 & 2.6 & -8.1 & 42.1 \\
\hline & $\mathrm{ACh}$ & 211.1 & 149.1 & 128.6 & 2.4 & -9.0 & 38.6 \\
\hline & $\mathrm{CHOL}$ & 210.6 & 160.2 & 119.0 & 4.4 & -2.5 & 36.1 \\
\hline & $\mathrm{CH}$ & 211.43 & 114.45 & 56.59 & 6.6 & 4.28 & 46.36 \\
\hline & $\mathrm{CHCL}$ & 210.8 & 162.5 & 99.5 & 3.6 & -4.9 & 35.6 \\
\hline & PC & 211.2 & 158.3 & 100.6 & 2.6 & -8.1 & 36.5 \\
\hline & INN & 211.6 & 100.1 & 57.7 & 7.3 & 6.5 & 49.5 \\
\hline \multirow[t]{7}{*}{ Excluded ALA } & Control & 212.55 & 109.71 & 109.54 & 3.08 & -8.15 & 47.29 \\
\hline & $\mathrm{ACh}$ & 213.97 & 114.86 & 108.93 & 3.05 & -6.89 & 45.96 \\
\hline & $\mathrm{CHOL}$ & 214.95 & 109.12 & 82.4 & 6.4 & 3.7 & 47.2 \\
\hline & $\mathrm{CH}$ & 213.72 & 73.81 & 56.59 & 8.3 & 9.59 & 55.22 \\
\hline & $\mathrm{CHCL}$ & 213.08 & 122.12 & 63.32 & 4.94 & -0.93 & 44.43 \\
\hline & PC & 215.36 & 108.53 & 57.67 & 3.81 & -4.5 & 47.22 \\
\hline & INN & 212.7 & 67.68 & 31.24 & 8.66 & 10.73 & 56.73 \\
\hline
\end{tabular}

Note: ACh: acetylcholine; CHOL: choline; CHCL: choline chloride; $\mathrm{CH}$ : choline hydroxide; INN: citicoline; PC: phosphatidylcholine. ALA: alpha-linolenic acid. CN: cetane number; SV: saponification; IV: iodine value; DU: degree of unsaturation; LCSF: long-chain saturation factor; CFPP: cold filter plugging point. No drug treatments were used as control. All data were expressed as the mean of three separate tests. 


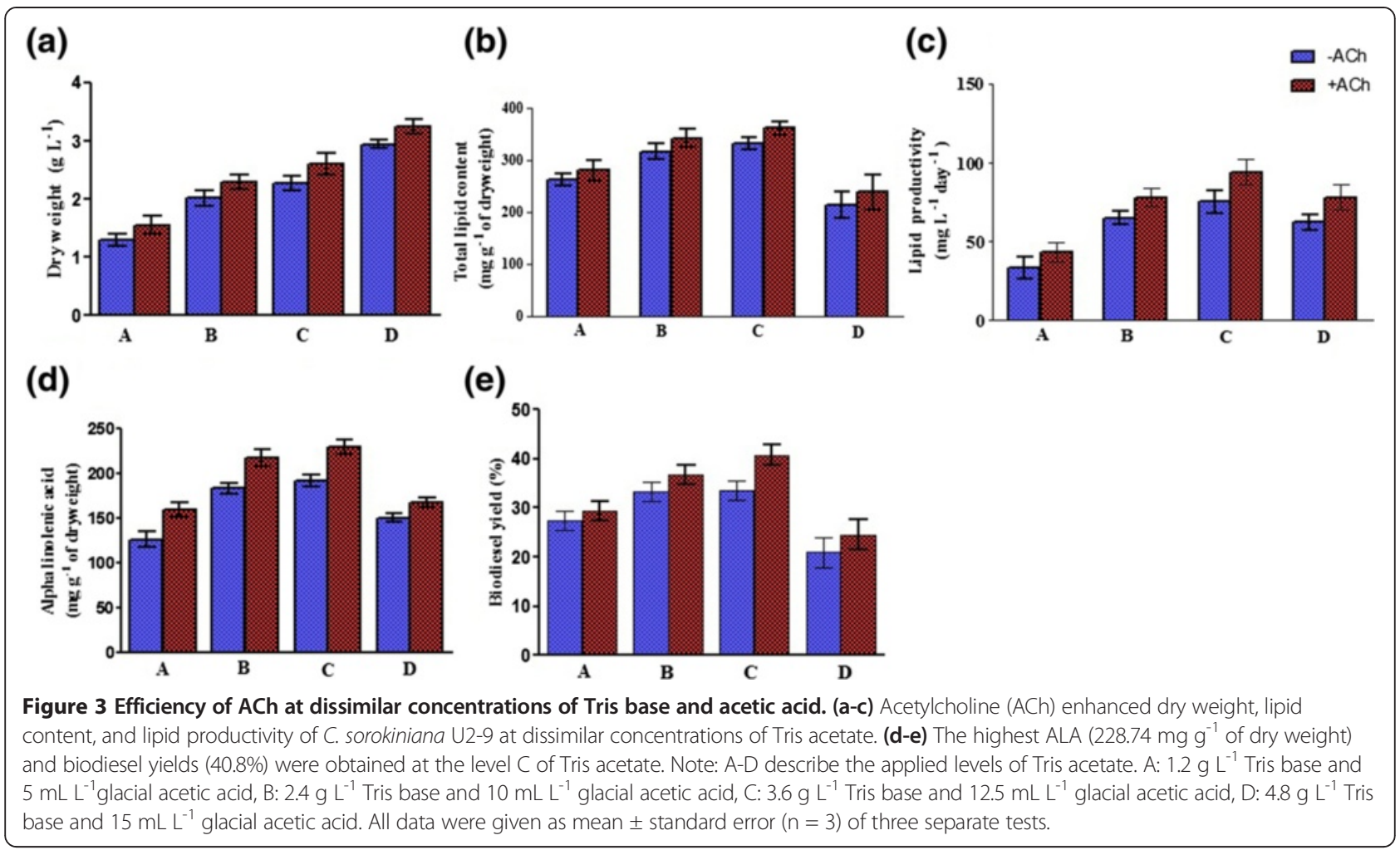

\section{(a)}

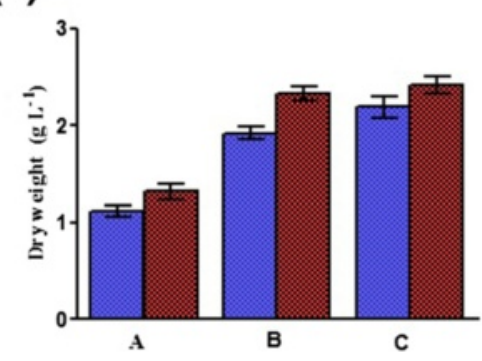

(d)

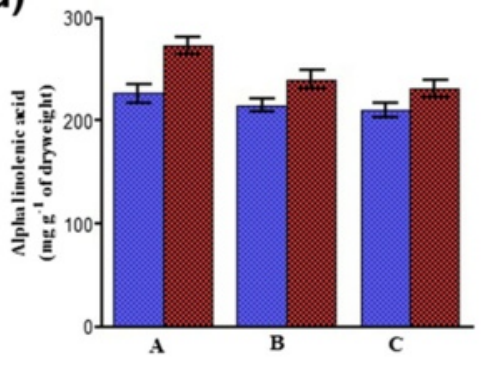

(b)

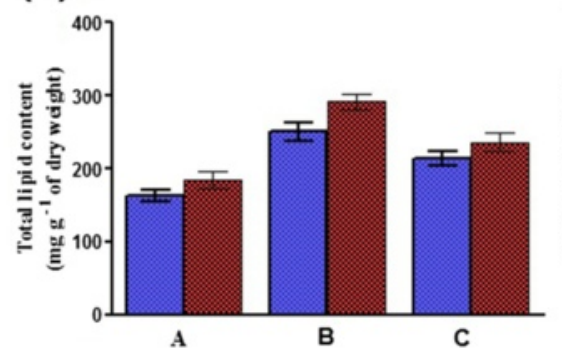

(e)

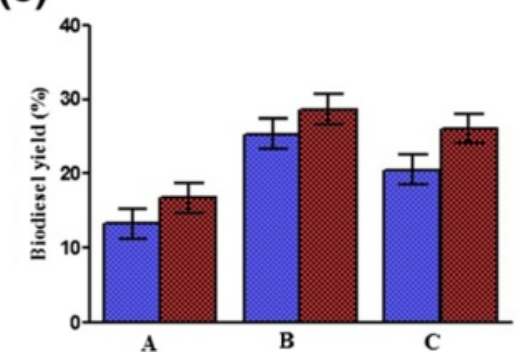

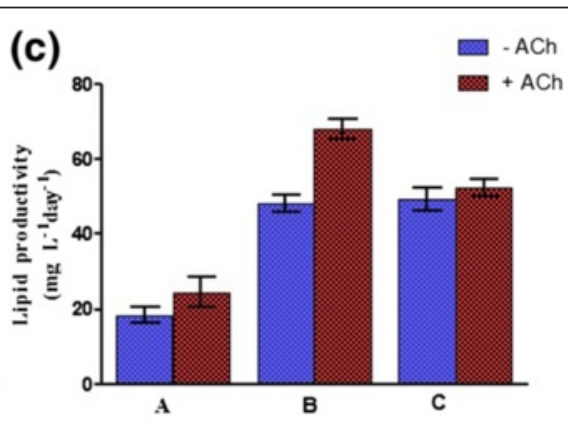

Figure 4 Effectiveness of ACh at the altered levels of phosphate buffer. (a-c) ACh improved the dry weight, lipid content, and lipid productivity of C. sorokiniana U2-9 at the altered phosphate buffer levels. (d) The highest ALA content was determined to be $272.43 \pm 8$ mg $\mathrm{g}^{-1}$ of dry weight at level $\mathrm{A}$ of phosphate buffer $+\mathrm{ACh}$. (e) Biodiesel yield was increased up to $28.8 \pm 2 \%$ at level $\mathrm{B}$ of phosphate buffer $+\mathrm{ACh}$. Note: A-C describe the applied levels of phosphate buffer. A: $\mathrm{Na}_{2} \mathrm{HPO}_{4}: 5.8 \mathrm{~g} \mathrm{~L}^{-1}, \mathrm{KH}_{2} \mathrm{PO}_{4}: 3.63 \mathrm{~g} \mathrm{~L}{ }^{-1}, \mathrm{~B}: \mathrm{Na}_{2} \mathrm{HPO}_{4}: 11.62 \mathrm{~g} \mathrm{~L}^{-1} \mathrm{KH}_{2} \mathrm{PO}_{4}: 7.26 \mathrm{~g} \mathrm{~L}$, $\mathrm{C}: \mathrm{Na}_{2} \mathrm{HPO}_{4}: 17.42 \mathrm{~g} \mathrm{~L}^{-1}, \mathrm{KH}_{2} \mathrm{PO}_{4}: 10.89 \mathrm{~g} \mathrm{~L}^{-1}$. All data were given as mean \pm standard error $(\mathrm{n}=3)$ of three separate tests. 


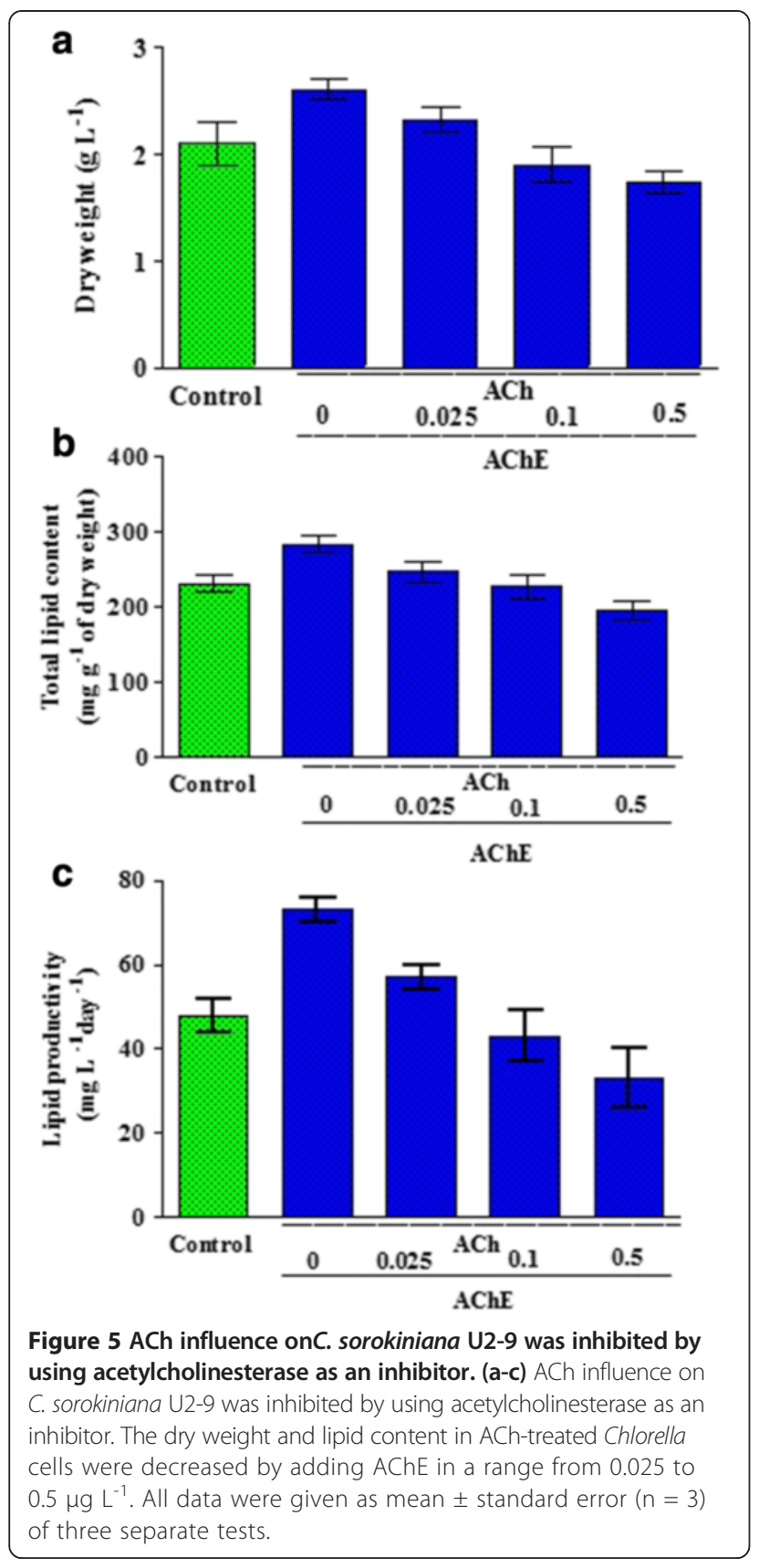

\section{Generalization of ACh effects among species of the Chlorella genus}

Chlorella kessleri UTEX 263, Chlorella vulgaris UTEX 395, and Chlorella protothecoides UTEX 256 were used to identify whether ACh has a general effectiveness through the Chlorella genus. As shown in Figure 1, ACh treatments contributed to higher biomass yields and higher total lipid contents by 20.6 to $43.7 \%$ and 15.5 to $19.0 \%$ over controls, respectively. The ALA contents in C. protothecoides UTEX 256 and C. vulgaris UTEX 395 were also improved by ACh up to $30.5 \%$ and $27.43 \%$, respectively (Additional file 1: Table S-5).
Table 3 AChE neutralized ACh stimulatory action on ALA production

\begin{tabular}{llllll}
\hline & & & \multicolumn{4}{l}{ Doses of AChE $\left(\boldsymbol{\mu g ~ ~ ^ { - 1 } )}\right.$} \\
\cline { 5 - 7 } FAS (\%) & $\mathbf{0}$ & ACh & $\mathbf{0 . 0 2 5}$ & $\mathbf{0 . 1}$ & $\mathbf{0 . 5}$ \\
\hline C14:0 & 6.5 & 3.9 & 4.1 & 4.5 & 6.4 \\
C16:0 & 33.2 & 22.5 & 24.3 & 26.0 & 29.7 \\
C16:1 & 8.0 & 8.8 & 8.6 & 9.2 & 8.8 \\
C16:2 & 3.2 & 5 & 5.1 & 4.7 & 3.8 \\
C16:3 & 4.2 & 11.6 & 11.7 & 10.8 & 5.8 \\
C18:0 & 10 & 2.0 & 2.7 & 3.0 & 7.8 \\
C18:1 & 4.1 & 1.6 & - & - & 4.7 \\
C18:2 & 16.2 & 18.2 & 18.6 & 17.9 & 16.2 \\
C18:3 & 14.2 & 26.2 & 24.6 & 23.6 & 16.6 \\
\hline
\end{tabular}

Note: ACh influence on production of ALA was reduced using AChE as an ACh inhibitor. ACh was applied at $5 \mu \mathrm{g} \mathrm{L}^{-1}$ at the initial phase of algal growth (data are presented as mean of three replicates).

\section{Effectiveness of ACh precursor and analogs on C.} sorokiniana U2-9

Since we found that ACh had a broad effectiveness on different Chlorella species, we attempted to analyze whether the generality exists in the ACh precursor and analogs too. For this purpose, the precursor choline (CHOL) and four analogs (choline chloride ( $\mathrm{CHCL}$ ), choline hydroxide $(\mathrm{CH})$, citicoline (INN) and phosphatidylcholine (PC)) were selected for the study.

The dry weight and the total lipid content were improved by all doses of ACh precursor and analogs, and our data uncovered the following order in the efficiency of ACh precursor and analogs: $\mathrm{CHOL}>\mathrm{PC}>\mathrm{CHCL}>$ $\mathrm{CH}>\mathrm{INN}$. The maximal increases in the dry weight, the total lipid content, and the lipid productivity were up to $5.17 \mathrm{~g} \mathrm{~L}^{-1}, 354 \mathrm{mg} \mathrm{g}^{-1}$ of dry weight, and $182 \mathrm{mg} \mathrm{L}^{-1}$ day $^{-1}$, respectively, by a $200 \mu \mathrm{g} \mathrm{L} \mathrm{L}^{-1}$ dosage of choline. We noticed that the ACh precursor and analog concentrations (up to $200 \mu \mathrm{g} \mathrm{L}^{-1}$ ) deployed were higher than that of $\mathrm{ACh}$ $\left(5 \mu \mathrm{g} \mathrm{L}^{-1}\right)$, and this dissimilarity might be due to differences in their modes of action. ACh might function as a regulator just as it works as a neurotransmitter in neurons; therefore, low concentrations could be sufficient to initiate a response. However, its precursor and analogs, for example, choline chloride, might function as a nutrient to fulfill the membrane development, and therefore higher concentrations would be needed.

The analysis of the fatty acid composition with ACh treatments indicated that the highest amount of ALA (31.08\%) was achieved with a $200 \mu \mathrm{g} \mathrm{L}^{-1}$ dosage of CHOL; conversely, the lowest ALA production was obtained by INN (ALA production was decreased by $75.30 \%$ with a $200 \mu \mathrm{g} \mathrm{L}^{-1}$ dosage of INN).

The biodiesel yield was improved by the ACh precursor and analogs, although CHOL and CHCL were more efficient (Figure 2), and the IV and the CFPP were 
enhanced by ACh precursors and analogs except that the IV was reduced by 14 to $44 \%$ after using INN.

The biodiesel quality was also modified by some of the ACh precursors and analogs. As shown in Additional file 1: Table S-6, choline treatments obviously reduced the $\mathrm{CN}$ but also increased the IV of biodiesel. In contrast, citicoline treatments generated reversed effects on biodiesel. Changes in the ALA levels of the fatty acid profiles probably explain their differential effects, since the biodiesel quality is negatively determined by the percentage of polyunsaturated fatty acids (including ALA).

Choline and its derivatives have been identified in several microalgal species or have shown functions to microalgal physiology [26,27]. For example, 0.001 to $0.32 \%$ of the dry weight of microalgal species (for example, Chlorophyta, Rhodophyta, Phaeophyta, and Euglenophyta) is composed of choline. Synthetic choline derivatives such as choline chloride and (2-chloroethyl) trimethylammonium chloride are potent in increasing lipid contents of microalgal species $[26,27]$. Our current research distinguished two kinds of modes of action for choline and its derivatives. Briefly, they have achieved similar effects on the accumulation of total lipids as well as ALA but at different dose levels. The effective doses of acetylcholine are at least tenfold lower than those of choline and its other derivatives. We hypothesized that acetylcholine might function as a signaling molecule, while choline and its other derivatives function as nutrient molecules. More work is required to elucidate the underlying mechanisms.

In recent years, many researchers have attempted to improve microalgal lipid yields using different techniques including genetic engineering of important enzymes (such as acetyl-CoA carboxylase) of the lipid metabolism. Reports from the National Renewable Energy Laboratory in the USA indicate that the lipid contents of engineered microalgae were increased up to $60 \%$ and $40 \%$, respectively, in laboratory and outdoor cultivations [28,29]. Besides the genetic techniques, the application of small bioactive molecules (such as ACh) offers an additional approach for the manipulation of microalgal biomass, lipid content, and fatty acid composition, as confirmed by this study.

The significance of the chemical approach based on small bioactive molecules might be summarized into three aspects. First, the small compounds offer a flexible technique which is easy to use and easy to integrate into the current production system of microalgae. Second, the small compounds promote the accumulation of both total lipids and high-value polyunsaturated fatty acids including ALA which could in turn reduce the costs of the microalgal production system, if the current methods to improve lipid yields are considered costly or time-consuming [30-32]. Third and more interestingly, the increased ALA yields with small compounds might offer a driving force to scale up biodiesel production from microalgae.
We preliminarily estimated the cost and profit of an optimized algal production system by $\mathrm{ACh}$ and its analogs which apparently supports the hypothesis of the driving force. The price of $250 \mathrm{mg}$ ALA in the current market is 60 US dollars (\$), while ACh and its cheap analogs (such as choline chloride) are at prices of 0.2 to $17.2 \$$ per $10 \mathrm{mg}$. When ACh and its analogs are used at 1 or $200 \mu \mathrm{g} \mathrm{L}^{-1}$ in a one-liter culture system for 10 days to generate a net increase in ALA yield by $140 \mathrm{mg}$, the profit reaches $34 \$$ (ALA) at a cost of $0.02 \$$ (small compounds). After ALA is separated, the rest of the fatty acids are transesterified into biodiesel with improved quality. The separation strategy should be optimized in future work. With everything taken together, ALA as a driving force to scale up biodiesel production might be considered.

\section{Conclusions}

Based on our findings, we propose that non-neuronal ACh has a stimulatory role in growth and lipid accumulation of Chlorella species, and the exogenous usage of ACh at miniature doses promotes yields of biomass, lipids, and ALA. ACh and its precursor and analogs can be used as enhancers in a photoautotrophic microalgal production system for simultaneous production of ALA as a high-value fatty acid and lipid feedstock for biodiesel production. Moreover, microalgal ALA could drive biodiesel production economically and could improve biodiesel quality by the separation of ALA from the fatty acid mixture.

\section{Methods}

Microalgal strain, growth conditions and acetylcholine doses Chlorella sorokiniana U2-9 belonging to the phylum Chlorophyta was chosen as a standard microalga in our study. The microalgae were maintained in $100 \mathrm{~mL}$ of TrisAcetate-Phosphate (TAP) medium in 250-mL Erlenmeyer flasks under a 14-hour light [4800 (lux)]/10-hour dark cycle; the temperature was adjusted to $27^{\circ} \mathrm{C}$, and the inoculation density was arranged on $\mathrm{OD}_{680}=0.042$.

ACh was purchased from the Sigma Aldrich company $(\geq 99 \%)$, and it was dissolved in deionized water and then added to the medium by a syringe filter with $0.2-\mu \mathrm{m}$ pore size at three different algal growth stages (initial, exponential, and stationary) at $0.125,0.25,0.5,1,5$, and $10\left(\mu \mathrm{g} \mathrm{L}^{-1}\right)$ doses. The growth of algae was monitored by the optical density of the cultures at $680 \mathrm{~nm}$, and $\mathrm{OD}_{680}$ values of $1.62 \pm 0.15$ and $3.15 \pm 0.1$ were obtained for exponential and stationary phases of algal growth, respectively.

\section{Detection of endogenous acetylcholine and usage of acetylcholinesterase}

An EnzyChrom acetylcholine assay kit (EACL-100) was used for identification and quantification of $\mathrm{ACh}$ in $C$. sorokiniana U2-9, and the samples were analyzed using a 
GloMax-Multi Detection System (Promega). To estimate the actual influence of $\mathrm{ACh}, 0.025,0.1$, and $0.5 \mu \mathrm{g} \mathrm{L} \mathrm{L}^{-1}$ doses of acetylcholinesterase (AChE, as an ACh inhibitor, with activity $\geq 200$ unit $^{-1}$ ) was used with a $5 \mu \mathrm{g} \mathrm{L}^{-1}$ dosage of ACh.

\section{Assessment of acetylcholine effectiveness at varied nutrition levels of media}

Sets of experiments were conducted by altered levels of Tris acetate (TA) and phosphate buffer (PB) when a $5 \mu \mathrm{g} \mathrm{L}{ }^{-1}$ dosage of ACh was included in the media to evaluate the stability of ACh at the altered culture conditions. In the first set of experiments, four levels of Tris acetate buffer with a $5 \mu \mathrm{g} \mathrm{L}^{-1}$ dosage of ACh were used (A:1.2 $\mathrm{g} \mathrm{L}^{-1}$ Tris base and $5 \mathrm{~mL} \mathrm{~L}^{-1}$ glacial acetic acid, B: $2.4 \mathrm{~g} \mathrm{~L}^{-1}$ Tris base and $10 \mathrm{~mL} \mathrm{~L}^{-1}$ glacial acetic acid, C: $3.6 \mathrm{~g} \mathrm{~L}^{-1}$ Tris base and $12.5 \mathrm{~mL} \mathrm{~L}^{-1}$ glacial acetic acid, D: $4.8 \mathrm{~g} \mathrm{~L}^{-1}$ Tris base and $15 \mathrm{~mL} \mathrm{~L}^{-1}$ glacial acetic acid). In the second set of experiments, three levels of phosphate buffer with a $5 \mu \mathrm{g} \mathrm{L}-1$ dosage of ACh were used $\left(\mathrm{A}: \mathrm{Na}_{2} \mathrm{HPO}_{4}: 5.8 \mathrm{~g} \mathrm{~L}^{-1}\right.$, $\mathrm{KH}_{2} \mathrm{PO}_{4}: 3.63 \mathrm{~g} \mathrm{~L}^{-1}, \mathrm{~B}: \mathrm{Na}_{2} \mathrm{HPO}_{4}: 11.62 \mathrm{~g} \mathrm{~L}^{-1}, \mathrm{KH}_{2} \mathrm{PO}_{4}$ : $\left.7.26 \mathrm{~g} \mathrm{~L}^{-1}, \mathrm{C}: \mathrm{Na}_{2} \mathrm{HPO}_{4}: 17.42 \mathrm{~g} \mathrm{~L}^{-1}, \mathrm{KH}_{2} \mathrm{PO}_{4}: 10.89 \mathrm{~g} \mathrm{~L}^{-1}\right)$.

ACh effectiveness on other species of the Chlorella genus A $5 \mu \mathrm{g} \mathrm{L}^{-1}$ dosage of ACh was deployed at the initial growth phase of C. kessleri UTEX 263, C. vulgaris UTEX 395, and C. protothecoides UTEX 256 to evaluate the effectiveness of ACh on other species of Chlorella.

\section{Usage of acetylcholine precursor and analogs}

Choline (CHOL), choline chloride (CHCL), choline hydroxide $(\mathrm{CH})$, citicoline (INN), and phosphatidylcholine (PC) were used in doses of 50,150, and $200 \mu \mathrm{g} \mathrm{L}^{-1}$ in the TAP medium to analysis the efficiency of the ACh precursor and analogs on C. sorokiniana U2-9.

\section{Analysis of growth, biomass and total lipid contents of C. sorokiniana}

The growth of $C$. sorokiniana U2-9 was monitored by optical density $\left(\mathrm{OD}_{680}\right)$ with a spectrophotometer device (T80 UV/VIS spectrometer), and the dry weight $\left(\mathrm{g} \mathrm{L}^{-1}\right)$ and the total lipid content ( $\mathrm{mg} \mathrm{g}^{-1}$ of dry weight) were obtained at three days past the stationary phase. The lipid productivity $\left(\mathrm{mg} \mathrm{L}^{-1} \mathrm{day}^{-1}\right.$ ) was calculated using the following formula:

$$
\text { Lipid productivity }=\mathrm{CL} / \mathrm{t}
$$

where $\mathrm{CL}$ is the concentration of lipids $\left(\mathrm{mg} \mathrm{L}^{-1}\right)$ at the end of the culture and $t$ is the duration of the culture (day).

\section{Extraction of lipids and transesterification}

The obtained biomass from stationary phase was placed in 50-mL centrifuge tubes, $4 \mathrm{~mL}$ distilled water and $5 \mathrm{~mL}$ hydrochloridric acid $(\mathrm{HCl})$ were added, and the samples were heated at $70^{\circ} \mathrm{C}$ in a water bath for 20 minutes. Afterward, $5 \mathrm{~mL}$ of ethanol was added, and the samples were cooled naturally at room temperature. Then $10 \mathrm{~mL}$ diethyl ether was added, and the samples were shaken and centrifuged (4000 rpm) for 1 and 2 minutes, and the ether layer was gathered into round flask; the process was repeated three times. Lastly, the total lipid content was obtained by evaporation of ether using a rotary evaporator. At the transesterification step, the obtained lipid was dissolved in chloroform and transferred into a $1.5-\mathrm{mL}$ glass vial. Subsequently $1 \mathrm{~mL} 1 \mathrm{M}$ sulphuric acid-methanol was added to the sample, and it was maintained for 1 hour at a temperature of $100^{\circ} \mathrm{C}$. The samples were cooled naturally, and $500 \mu \mathrm{L}$ distilled water was added and mixed by shaking for 2 minutes. Finally the samples were extracted with $\mathrm{n}$-hexane three times, the organic phases were gathered and dried under nitrogen gas, and the obtained methyl ester was weighed.

\section{Fatty acid profiling analysis}

A gas chromatography (GC) unit consisting of a FID detector (Agilent 7890) and a DB-WAX column $(30 \mathrm{~m} \times 0.32$ $\mathrm{mm} \times 0.50 \mu \mathrm{m})$ was used to determine the fatty acid content and composition of the samples. Methyl undecanoate was used as an internal standard and the analysis program was set as follows:

The temperature program comprised three phases; initially the temperature was increased from $50^{\circ} \mathrm{C}$ to $150^{\circ} \mathrm{C}$ at a rate of $10^{\circ} \mathrm{C}$ per minute, and held for 2 minutes; then the temperature was increased to $200^{\circ} \mathrm{C}$ from $150^{\circ} \mathrm{C}$ at a rate of $10^{\circ} \mathrm{C}$ per minute, and held for 6 minutes; and finally the temperature was increased to $230^{\circ} \mathrm{C}$ from $200^{\circ} \mathrm{C}$ at a rate of $10^{\circ} \mathrm{C}$ per minute, and held for 5 minutes. Carrier gas $\left(\mathrm{N}_{2}\right)$ velocity: $3 \mathrm{~mL}$ per minute. Detector: hydrogen flame detector, the velocity of $\mathrm{H}_{2}$ was $30 \mathrm{~mL}$ per minute, and the velocity of air was $300 \mathrm{~mL}$ per minute. The detector temperature and injector temperature were adjusted to 300 and $280^{\circ} \mathrm{C}$, respectively.

\section{Estimation of biodiesel properties by using fatty acid profiles}

The biodiesel yield and parameters of biodiesel quality were estimated by the molecular structure of fatty acids using a set of formulas described by Nascimento and colleagues [25].

(1) Biodiesel yield = fatty acid methyl ester/algae biomass* lipid content

(2) Saponification (SV) and Iodine value (IV)

$$
\mathrm{SV}=\Sigma(560 * \mathrm{~N}) / \mathrm{MIV}=\Sigma(254 * \mathrm{DN}) / \mathrm{M}
$$

where $\mathrm{D}$ is number of double bonds, $\mathrm{M}$ is fatty acid (FA) molecular mass, and $\mathrm{N}$ is the percent of each FA. 
(3) Cetane number $(\mathrm{CN})$ was calculated based on SV and IV.

$$
\mathrm{CN}=46.3+(5458 / \mathrm{SV})-(0.225 * \mathrm{IV})
$$

Degree of unsaturation (DU)

(4) $\mathrm{DU}=$ MUFA $+(2 *$ PUFA $)$

where MUFA is monounsaturated fatty acid and PUFA is polyunsaturated fatty acid.

(5) Long chain saturation factor (LCSF)

$\mathrm{LCSF}=\left(0.1^{*} \mathrm{C} 16\right)+\left(0.5^{*} \mathrm{C} 18\right)+(1 * \mathrm{C} 20)+\left(1.5^{*} \mathrm{C} 22\right)+$ $(2 * \mathrm{C} 24)$

where C16, C18, C20, C22, C24 are weight percentage of each fatty acid.

(6) Cold filter plugging point (CFPP) calculated based on LCSF

CFPP $=(3.1417 *$ LCSF $)-16.477$.

\section{Additional file}

Additional file 1: Supplementary supporting data. Table S-1. The effects of ACh on growth and lipid accumulation in C. sorokiniana U2-9 at different growth stages. Table S-2. Fatty acid profiles and estimated properties of biodiesel of C. sorokiniana U2-9 under ACh doses at different growth stages. Table S-3. Fatty acid profiles and estimated properties of biodiesel at different levels of Tris base and acetic acids. Table S-4. Fatty acid profiles and estimated properties of biodiesel at different phosphate buffer levels. Table S-5. Profiles of fatty acids and estimated properties of biodiesel from different species of the Chlorella genus. Table S-6. Comparative fatty acid profiles (\%) and estimated biodiesel properties affected by precursor and analogs of acetylcholine at different doses.

\section{Abbreviations}

ACh: Acetylcholine; ALA: Alpha-linolenic acid; CFPP: Cold filter plugging point; $\mathrm{CH}$ : Choline hydroxide; $\mathrm{CHCL}$ : Choline chloride; $\mathrm{CHOL}$ : Choline; CN: Cetane number; DU: Degree of unsaturation; INN: Citicoline; IV: Iodine value; LCSF: Long-chain saturation factor; PC: Phosphatidylcholine; SV: Saponification.

\section{Competing interests}

The authors declare that they have no competing interests.

\section{Authors' contributions}

AP and YFC designed the experiments, analyzed the data, and wrote the manuscript. AP carried out the majority of the experiments. ZS and XD maintained the Chlorella strains and carried out GC analysis of lipids. All authors read and approved the final manuscript.

\section{Acknowledgment}

This work was supported by the Jiangsu Agricultural Science and Technology Innovation Fund (number CX (12)3041 to Y-F Chen), the Program of Introduced High-level Innovative and Entrepreneurial Talents in Jiangsu Province (number 2012-10 to Y-F Chen), the Natural Science Foundation of Jiangsu Province (number BK20130712 to Z Sun), and the Postdoctoral Fellowship from the Jiangsu Academy of Agricultural Sciences, and the National Postdoctoral Science Fund of China (number 2014 M561602 to A Parsaeimehr).

\section{Author details}

${ }^{1}$ Laboratory of Biosystems Engineering, Institute of Biotechnology, Jiangsu Academy of Agricultural Sciences, Nanjing 210014, Jiangsu, China.

${ }^{2}$ Targetong Energy Co., Ltd, Nanjing 211800, Jiangsu, China.

Received: 4 June 2014 Accepted: 5 January 2015

Published online: 29 January 2015

\section{References}

1. Meher LC, Vidya Sagar D, Naik SN. Technical aspects of biodiesel production by transesterification - a review. Renew Sustain Energy Rev. 2006;10:248-68.

2. Chisti Y. Biodiesel from microalgae. Biotechnol Adv. 2007;25:294-306.

3. Chen $Y-F, W u$ Q. Production of biodiesel from algal biomass: Current perspectives and future. In: Pandey A, Larroche C, Ricke SC, Dussap CG, Gnansounou E, editors, editors. Biofuels: alternative feedstocks and conversion processes. Elsevier: Academic Press; 2011. p. 399-413.

4. Essential fatty acid [http://en.wikipedia.org/wiki/Essential_fatty_acid]

5. Demirbas A, Fatih Demirbas M. Importance of algae oil as a source of biodiesel. Energy Convers Manag. 2011;52:163-70.

6. Ruiz-Rodriguez A, Reglero G, Ibañez E. Recent trends in the advanced analysis of bioactive fatty acids. J Pharm Biomed Anal. 2010;51:305-26.

7. Jensen $\mathrm{CL}$, Prager TC, Fraley JK, Chen H, Anderson RE, Heird WC. Effect of dietary linoleic/alpha-linolenic acid ratio on growth and visual function of term infants. J Pediatr. 1997;131:200-9.

8. Liou YA, King DJ, Zibrik D, Innis SM. Decreasing linoleic acid with constant a-linolenic acid in dietary fats increases ( $n-3)$ eicosapentaenoic acid in plasma phospholipids in healthy men. J Nutr. 2007;137:945-52.

9. Franz AK, Danielewicz MA, Wong DM, Anderson LA, Booth JR. Phenotypic screening with oleaginous microalgae reveals modulators of lipid productivity. ACS Chem Biol. 2013;8:1053-62.

10. Micheau J, Marighetto A. Acetylcholine and memory: a long, complex and chaotic but still living relationship. Behav Brain Res. 2011;221:424-9.

11. Oliveira EE, Schleicher S, Büschges A, Schmidt J, Kloppenburg P, Salgado VL. Desensitization of nicotinic acetylcholine receptors in central nervous system neurons of the stick insect (Carausius morosus) by imidacloprid and sulfoximine insecticides. Insect Biochem Mol Biol. 2011;41:872-80.

12. Jia W, Zhang J. Stomatal movements and long-distance signaling in plants. Plant signaling and behavior. 2008;3:772-7.

13. Łukasiewicz-Rutkowska H, Tretyn A, Cymerski M, Kopcewicz J. The effect of exogenous acetylcholine and other cholinergic agents on photoperiodic flower induction of Pharbitis nil. Acta Soc Bot Pol. 1997:66:47-54.

14. Jones RS, Stutte CA. Acetylcholine and red-light influence on ethylene evolution from soyabean leaf tissues. Ann Bot. 1986;57:897-900.

15. Yamamoto K, Momonoki YS. Tissue localization of maize acetylcholinesterase associated with heat tolerance in plants. Plant signaling and behavior. 2012;7:301-5

16. Hoshino T. Effects of acetylcholine on the growth of the Vigna seedling. Plant Cell Physiol. 1983;24:551-6.

17. Horiuchi Y, Kimura R, Kato N, Fujii T, Seki M, Endo T, et al. Evolutional study on acetylcholine expression. Life Sci. 2003;72:1745-56.

18. Bossen ME, Tretyn A, Kendrick RE, Vredenberg WJ. Comparison between swelling of etiolated wheat (Triticum aestivum L.) protoplasts induced by phytochrome and a-naphthaleneacetic acid, benzylaminopurine, gibberellic acid, abscisic acid and acetylcholine. J Plant Physiol. 1991;137:706-10.

19. Roshchina W. Evolutionary considerations of neurotransmitters in microbial, plant, and animal cells. In: Mark L, Freestone PPE, editors. Microbial endocrinology. New York: Springer; 2010. p. 17-52.

20. Schiechl G, Himmelsbach M, Buchberger W, Kerschbaum HH, Lütz-Meindl U Identification of acetylcholine and impact of cholinomimetic drugs on cell differentiation and growth in the unicellular green alga Micrasterias denticulata. Plant Sci. 2008;175:262-6.

21. Wessler I, Kirkpatrick CJ, Racke K. The cholinergic 'pitfall': acetylcholine, a universal cell molecule in biological systems, including humans. Clin Exp Pharmacol Physiol. 1999;26:198-205.

22. Mann JJ, Brown RP, Halper JP, Sweeney JA, Kocsis JH, Stokes PE, et al. Reduced sensitivity of lymphocyte beta-adrenergic receptors in patients with endogenous depression and psychomotor agitation. N Engl J Med. 1985;313:715-20.

23. Barwell CJ. Acetylcholine in the red alga Laurencia obtusa (Huds.) Lamour. Bot Mar. 1980;23:63-4. 
24. Czerpak R, Bajguz A, Jewiec P, Muszynska-garstka M. The influence of acetylcholine and taurine on the content of some metabolites in the alga Chlorella vulgaris. Ecohydrol Hydrobiol. 2003;3:223-9.

25. Nascimento IA, Marques SSI, Cabanelas ITD, Pereira SA, Druzian JI, de Souza $\mathrm{CO}$, et al. Screening microalgae strains for biodiesel production: lipid productivity and estimation of fuel quality based on fatty acids profiles as selective criteria. BioEnergy Research. 2013;6:1-13.

26. Ikawa M, Borowski PT, Chakravarti A. Choline and inositol distribution in algae and fungi. Appl Microbiol. 1968;16:620-3.

27. Orcutt DM, Davis GA, Moore LD. The effects of choline derivatives on the growth and lipid content of continuously cultured Chlorella vulgaris. Can J Bot. 1984;62:81-5.

28. Hu Q, Sommerfeld M, Jarvis E, Ghirardi M, Posewitz M, Seibert M, et al. Microalgal triacylglycerols as feedstocks for biofuel production: perspectives and advances. Plant J. 2008:54:621-39.

29. Roessler PG, Bleibaum JL, Thompson GA, Ohlrogge JB. Characteristics of the gene that encodes acetyl-CoA carboxylase in the diatom Cyclotella cryptica. Ann N Y Acad Sci. 1994;721:250-6.

30. Huang G, Chen F, Wei D, Zhang X, Chen G. Biodiesel production by microalgal biotechnology. Appl Energy. 2010;87:38-46.

31. Xiong W, Li X, Xiang J, Wu Q. High-density fermentation of microalga Chlorella protothecoides in bioreactor for microbio-diesel production. Appl Microbiol Biotechnol. 2008;78:29-36.

32. Chen YH, Walker TH. Biomass and lipid production of heterotrophic microalgae Chlorella protothecoides by using biodiesel-derived crude glycerol. Biotechnol Lett. 2011;33:1973-83.

\section{Submit your next manuscript to BioMed Central and take full advantage of:}

- Convenient online submission

- Thorough peer review

- No space constraints or color figure charges

- Immediate publication on acceptance

- Inclusion in PubMed, CAS, Scopus and Google Scholar

- Research which is freely available for redistribution 